\title{
LANGUAGE EXPERIENCE AND PHONETIC TRAINING AS FACTORS INFLUENCING TIMING ORGANISATION IN POLISH LEARNERS OF ENGLISH
}

\author{
ANNA GRALIŃSKA-BRAWATA \\ University of Łódź \\ agrabra@uni.lodz.pl
}

\begin{abstract}
The paper investigates the dynamics of speech rhythm in Polish learners of English and, specifically, how rhythm measurements revealing durational characteristics of vocalic and consonantal intervals through the measures $(\% \mathrm{~V}, \Delta \mathrm{V}, \Delta \mathrm{C}, \mathrm{VarcoV}$, VarcoC and $\mathrm{nPVI})$ change along the process of second language acquisition as a result of language experience and phonetic training, and influence rhythmic characteristics of L2 English. The data used for the analysis come from 30 Polish first-year students of the University of Łódź recorded reading two texts (English and Polish) during two recording sessions separated by a 7-month period of language studies and compared to the data obtained from the recordings of native speakers of English. The experiment aims at verifying whether the participants achieve progress in the rhythm measure scores under the influence of language experience and phonetic training, as it has already been confirmed that general proficiency of non-native speakers of English is a key factor contributing to the successful production of rhythmic patterns in English (Waniek-Klimczak 2009, Roach 2002). The results have shown no substantial and consistent progress for the whole group and across all the measures. Statistical tests, however, have revealed significant changes in the subjects' performance with respect to the vocalic measures $\Delta \mathrm{V}$ and VarcoV. This may reflect the effect of the type of phonetic training the students are offered, which is segment-based with particular emphasis on vowels.
\end{abstract}

Keywords: non-native speech rhythm, rhythm measures

\section{Introduction}

The rhythm of speech is generally understood in terms of the arrangement of alternating stressed and unstressed elements, which are considered temporal organisational units. These elements vary between languages that have been claimed to fall into stress-timed and syllable-timed classes (Pike 1945, Abercrombie 1967), the identity of which, together with the concept of isochrony, has long been the subject of heated discussions. Instead of clear-cut categories between rhythm classes, Dauer $(1983,1987)$ proposed a model according to which languages can be located on a continuum based on phonetic and phonological criteria with typically stress-timed languages at one end and typically syllable-timed languages at the other end. This model contributed to the development of acoustic correlates of rhythm, or rhythm measures (metrics) that seem to give some 
evidence for the existence of quantitative rhythmic differences between rhythm classes. The most commonly used include:

- $\% \mathrm{~V}$ - timing proportions of vocalic intervals in an utterance (Ramus et al.1999),

- $\Delta \mathrm{V}$ and $\Delta \mathrm{C}$ - standard deviation of vocalic and consonantal intervals (Ramus et al. 1999),

- nPVI (normalised Pairwise Variability Index) - the mean of the differences between successive vocalic intervals divided by the sum of these intervals (Grabe and Low 2002),

- VarcoV and VarcoC - standard deviation of vocalic and consonantal intervals divided by the mean vocalic interval duration (Dellwo and Wagner 2003, White and Mattys 2007). ${ }^{1}$

The measures are based on timing relations between vocalic and consonantal durations, and on the conviction that rhythm type depends on consonantal and vocalic variability.

Motivations for investigating the rhythm of speech are numerous, and commonly are grounded within the context of language teaching (see e.g. Adams 1979), as it is believed that linguistic rhythm contributes substantially to the intelligibility of foreign speech and, consequently, it is one of the most important acquisition targets for language learners. To confirm the importance of rhythm in English over other elements on the lexical level of the language, it is claimed that in the case of foreign speech, poorly pronounced words that conform to the right rhythm have more chances to be intelligible than correctly articulated words with wrong rhythmic structure; in other words, correct rhythmic patterns in L2 speech enhance intelligibility (Avery and Ehrlich 1992, Roach 2002).

\subsection{Rhythmic status of English and Polish}

The rhythmic status of English is undisputable. From the beginnings of speech rhythm studies, it has frequently been described as a prototypical stress-timed language (Abercrombie 1967: 97, Dauer 1983: 56, Laver 1994: 529) with a tendency for complex syllable structures, variable stress pattern and vowel reductions.

The rhythmic status of Polish is an interesting and unresolved issue as no consensus among phoneticians and phonologists has been reached with regard to its affiliation with stress- or syllable-timed class of languages (e.g. Hayes and Puppel 1985). Rubach and Booij (1985) claim that Polish, although not as typical as English or Russian, is a stresstimed language. Avery and Ehrlich, on the other hand, argue that "Polish is a syllabletimed language and lacks the reduction of vowels so important to English rhythm" (1992: 145). In more recent literature describing Polish rhythmic structure, most attention is devoted to the fact that it appears to be a mixed-type language. It is due to the fact that its features do not match those of typically stress- or syllable-timed

\footnotetext{
${ }^{1}$ There are other rhythm measures introduced to speech rhythm investigations, e.g. rPVI-C (Grabe and Low 2002), PVI-CV(Barry et al. 2003), med nPVI-V, med rPVI-C (Ferragne and Pellegrino 2004), nPVI-CV (Asu and Nolan 2005), YARD (Wagner and Dellwo 2004). These are not discussed in the paper as they are not employed in the project presented here.
} 
languages (Dauer 1987, Nespor 1990, Ramus et al. 1999). Namely, Polish presents a large variety of syllable types and great syllable complexity, which places it among stress-timed languages. However, it exhibits no phonological vowel reduction at normal speech rates, a characteristic of syllable-timed languages.

\subsection{Second language rhythm and rhythm metrics}

The studies investigating second language acquisition of English rhythm with the application of rhythm measures in general point to the considerable impact of L1 phonological system (e.g. Low et al. 2000 for Singapore English; Jian 2004 for Taiwanese English; Mok and Dellwo 2008 for Cantonese and Mandarin English) and English proficiency level of L2 speakers on the rhythm metrics (e.g. Ordin et al. 2011 for German English; Shport 2009 for Japanese English).

Research on Polish or Polish English with the use of rhythm metrics is scarce. The experiments conducted by Grabe and Low (2002) and Wagner (2012) belong, to the best knowledge of the author of this paper, to the very few studies that employ calculations of rhythm metrics. The results of their work show that L1 timing patterns and its phonotactic structure are observable factors influencing rhythm metrics. This is true particularly in terms of the variability of vocalic interval duration as "segmental parameter of vowel duration (is an element) deciding about the temporal organisation at higher levels" (Waniek-Klimczak 2005: 9).

Generally, when it comes to the acquisition of English rhythm in the context of L2 speech, the main stages in the development of appropriate timing relations follow similar patterns in the case of both native and non-native speakers, pointing to proficiency as the factor responsible for producing more adequate rhythm (Waniek-Klimczak 2009).

\section{Experiment}

This paper investigates the effect of L2 training on the rhythmic organisation of English in Polish advanced learners of English, adopting an acoustic phonetics approach to describe rhythm in terms of temporal speech measures. The main assumption adopted in the present study is that increased language experience and phonetic training that Polish learners of English are offered during English studies at university level, affects timing organisation in Polish speakers of English. It is based on the belief that the potential difficulties related to English rhythm that Polish learners of English have, are mainly caused by insufficient fluency and general proficiency in their L2 rather than the stress vs. syllable timed characteristics of English vs. Polish. In view of the recent research, the process of L2 rhythm acquisition of Polish students proceeds in a similar way as in English children who pass through a syllable-timing phase before they are able to perform proper reductions and other prosodic features typical of stress-timing at around 4 years of age. This is grounded in the statement made by Waniek-Klimczak who claims that "a gradual shift towards stress-timing organization of English follows a natural developmental process. It is the stage in second language acquisition and not first language interference that is the main source of difficulty in the acquisition of stress- 
based English rhythm for native speakers of Polish" (2009: 377). The study also aims to verify the usefulness of selected rhythm metrics proposed in the literature for the study of L2 English.

The following research questions have been formulated:

- Does Polish L1 influence the production of English L2 on the rhythmic level of speech as performed by Polish advanced learners of English? If yes, is the influence reflected through rhythm metrics?

- Does language experience and phonetic training that Polish learners of English are offered during English studies at a university level, affect timing organisation in Polish speakers of English? If yes, what is the direction of change and which rhythm metrics can reflect progress?

\subsection{Participants}

The data used for the analysis come from 30 Polish first-year students of English at the University of Łódź aged between 19-24. The recording for the present study took place while the respondents attended numerous courses in English as part of the major programme of their studies, which ensures considerable exposure to the language. The phonetic training the students are offered provides intensive input directing their attention to various pronunciation issues, however it is not focused on the rhythm itself. The syllabus of the practical phonetics course for first-year students concentrates mostly on recognising, discriminating and producing the sounds of English on the segmental rather than suprasegmental level of British English standard pronunciation, with some very basic hints of such prosodic elements as prominence, rhythm and intonation.

The selection of participants was not controlled for subjective perception of native/non-native accent or objective fluency tests. All first-year students are expected to meet the requirements of intermediate or upper-intermediate level of language proficiency and they must pass the Matura exam at the extended level in English at the end of their secondary education.

Gender and the knowledge of other foreign languages were the variables that were not considered for the experiment, although subjects were asked to answer questions connected to their sex and the level of their proficiency in other foreign languages. Generally, females outnumbered males with the proportion of 25 to 5 .

\subsubsection{Reference group}

The recordings of non-native speech were compared to 11 native English speakers recorded for the purposes of the present experiment. Ten of them form a group assumed to speak standard British English. Their age ranged between 24 and 60 at the time of the recording. Five of them are female and five are male. All the speakers have similar educational background, terminating their education at university level and specialising in instrumental performance. 


\subsection{Materials}

The reading passage used in the experiment was one of Aesop's Fables, The North Wind and the Sun, frequently used in phonetic investigations (recommended by the IPA for indicating phonemic contrasts in English) or speech rhythm research (e.g. Grabe and Low 2002).

The material that has been selected for phonetic measurements consists of four phrases within which no pauses or breaks in the flow of speech are to be expected (see Appendix 1). The intention was to investigate phrases of different length and that is why Phrase 1 and Phrase 2 are longer (11 syllables each) and Phrase 3 and Phrase 4 are shorter (5 and 7 syllables).

\subsection{Procedure}

There were two recording sessions. The first session took place at the beginning of the winter semester (October 2009), prior to the practical phonetics course; the second was arranged at the end of summer semester (May 2010), close to the end of the course. Before the recording the participants were given time to read the text, and asked to read aloud highlighted words that the author predicted might cause some difficulty for Polish speakers, both in terms of word stress and vowel quality. These are as follows: wind, disputing, cloak, succeeded, blew, attempt, obliged. Having read and, if necessary, repeated aloud the problematic words, the subjects were asked to read the English text first in a natural manner with their normal tempo (defined in terms of Dellwo, 2010), then to read the same text faster, trying to make a noticeable difference between the two tempos. The whole procedure took place twice and was conducted in an identical way. All the speech samples used in the experiment (L2 and L1 English) were recorded with the use of MXL Studio 1 USB microphone directly to the laptop computer in the .wav format in a relatively quiet, but not soundproof room at the Institute of English Studies, University of Łódź. They were later segmented manually into vocalic and consonantal intervals with the use of Praat, version 5.0.29, mainly according to the criteria employed by Grabe and Low (2002). Both normal tempo and fast tempo variables are taken into consideration.

\subsection{Assessment criteria}

The experiment aims at verifying whether the participants achieve progress in rhythm measure scores under the influence of language experience and phonetic training. The calculated mean scores of each subject's performance in each of the two recording sessions were compared with the mean scores obtained by the group of native speakers. All the scores have been analysed separately for normal and fast speech. Progress is understood here as the tendency of the Polish subject scores in Recording 2 to approximate the native subject scores to a greater extent than in Recording 1.

Generally, the progress is marked with '+' and its lack is marked with '-'. There is no label for the individual performance that demonstrates the lack of change over time. 
Because the obtained scores differ to a various degree across rhythm measures, different assessment criteria have been chosen for identifying progress in each rhythm measure and for each participant.

- For $\% \mathrm{~V}$, which exhibits the smallest variability between scores, with the difference between mean values of minimum and maximum score being 13.6, progress has been defined in terms of the difference between Rec. 1 and Rec. 2 for both normal and fast tempo of speech is at least 0.5 .

- For $\Delta \mathrm{V}$, VarcoV and VarcoC and nPVI, which presents greater variability with the difference between mean values of minimum and maximum score being 43.5, 36.4, 43.6 and 44.7, progress is marked when the difference between Rec. 1 and Rec. 2 for both normal and fast tempo of speech is at least 1.0.

- For $\Delta \mathrm{C}$, which exhibits the greatest variability between scores with the difference between mean values of minimum and maximum score being 60.8, progress has been assumed when the difference between Rec. 1 and Rec. 2 for both normal and fast tempo of speech is at least 2.0.

Additionally, when no change defined above as progress is observed but both Rec.1 and Rec. 2 scores approximate or are identical with the native score, then they are rated as progress. This is motivated by the decision that progress is assessed by means of binary +/- system and choosing '-' could be unfair in a situation when pre- and post-training scores reflect the native normal and fast speech scores and no regress is observed. There are 11 such cases to be observed in the mean data for 4 phrases. If a rhythm metric score for Rec. 1 is higher than the corresponding native one and then changes its value in Rec. 2 to the one that is slightly below the native score, the change is treated as progress provided that Rec.2 score does not deviate from the native score by more than 1.5 for $\% \mathrm{~V}, 2.5$ for $\Delta \mathrm{V}, \Delta \mathrm{C}, \mathrm{VarcoV}, \mathrm{VarcoC}$ and $\mathrm{nPVI}$ and 8.0 for $\Delta \mathrm{C}$ (due to its considerable variability) and reflects the tendency of native performance (higher values for Rec.1 and lower values for Rec.2, or conversely lower values for Rec.1 and higher values for Rec.2). If this tendency is retained in non-native speech, but the scores exceed the ones obtained by native speakers by more 2.5 (in italics), no progress is assumed. There are several instances of obtaining reversed scores for normal and fast speech in L2 English and L1 English mean scores, i.e. Rec.1 fast tempo (F) score approximates native F score and Rec.2 F score approximates native normal tempo (N) score. For consistency reasons, in such situations no progress is marked, except when both $\mathrm{N}$ and $\mathrm{F}$ non-native scores have values falling between the $\mathrm{N}$ and $\mathrm{F}$ native values.

\subsection{Results and analysis}

Table 1 shows the average results for 30 Polish learners of English. '+' or '-' has been assigned to each of the measures for each individual learner according to the criteria described in the section above. The final column indicates the sum of ' $+\mathrm{s}$ ' achieved across all measures and tempos by individual participants. The two bottom lines provide the sum of pluses and the percentage of the achieved progress for all individual measures across all the 30 speakers. 


\begin{tabular}{|c|c|c|c|c|c|c|c|c|c|c|c|c|c|}
\hline \multicolumn{14}{|c|}{ Phrases 1-4 } \\
\hline & \multicolumn{2}{|c|}{$\% \mathrm{~V}$} & \multicolumn{2}{|c|}{$\Delta V$} & \multicolumn{2}{|c|}{$\Delta \mathrm{C}$} & \multicolumn{2}{|c|}{ VarcoV } & \multicolumn{2}{|c|}{ VarcoC } & \multicolumn{2}{|c|}{ nPVI } & \multirow[t]{2}{*}{ Sum } \\
\hline & $\mathbf{N}$ & $\mathbf{F}$ & $\mathbf{N}$ & F & $\mathbf{N}$ & $\mathbf{F}$ & $\mathbf{N}$ & $\mathbf{F}$ & $\mathbf{N}$ & $\mathbf{F}$ & $\mathbf{N}$ & F & \\
\hline 1 & - & - & + & - & + & + & + & - & + & - & - & + & 6 \\
\hline 2 & + & - & - & - & - & - & + & - & - & - & - & + & 3 \\
\hline 3 & + & - & + & - & - & + & + & - & - & + & + & - & 6 \\
\hline 4 & - & + & - & - & - & + & + & - & + & - & + & - & 5 \\
\hline 5 & - & + & - & - & - & - & + & + & + & - & + & - & 5 \\
\hline 6 & - & + & + & + & + & + & + & - & + & + & - & - & 8 \\
\hline 7 & - & - & + & + & - & + & + & - & - & + & + & - & 6 \\
\hline 8 & + & + & - & + & - & + & + & + & + & - & - & + & 8 \\
\hline 9 & - & - & + & + & - & - & - & - & - & + & + & - & 4 \\
\hline 10 & - & - & - & - & - & + & - & + & - & + & - & + & 4 \\
\hline 11 & - & + & + & - & + & + & - & + & + & + & - & + & 8 \\
\hline 12 & - & + & - & - & - & + & + & + & + & - & + & + & 7 \\
\hline 13 & - & + & - & - & - & + & + & - & - & - & + & - & 4 \\
\hline 14 & - & + & + & - & - & + & + & - & - & + & + & - & 6 \\
\hline 15 & - & - & - & - & - & - & - & - & + & + & - & - & 2 \\
\hline 16 & - & + & + & + & - & + & - & + & - & - & - & + & 6 \\
\hline 17 & - & - & - & + & - & + & + & - & + & + & - & - & 5 \\
\hline 18 & - & - & - & - & + & + & + & + & - & - & - & + & 5 \\
\hline 19 & + & - & + & - & - & + & - & - & + & - & - & - & 4 \\
\hline 20 & + & - & - & - & - & - & - & - & - & + & - & - & 2 \\
\hline 21 & + & + & + & - & + & + & + & + & + & - & + & + & 10 \\
\hline 22 & - & + & + & + & + & + & + & + & + & - & + & + & 10 \\
\hline 23 & - & - & - & + & - & + & + & - & - & + & - & - & 4 \\
\hline 24 & + & - & + & - & + & - & + & - & - & + & - & - & 5 \\
\hline 25 & + & + & + & - & - & - & + & + & - & - & - & - & 5 \\
\hline 26 & + & - & - & - & - & - & - & + & + & + & - & + & 5 \\
\hline 27 & + & - & - & - & - & + & - & - & - & - & - & - & 2 \\
\hline 28 & - & - & - & - & - & - & + & + & + & - & + & + & 5 \\
\hline 29 & + & + & + & + & + & + & - & - & + & + & + & + & 10 \\
\hline 30 & - & + & - & - & + & + & - & - & - & - & + & + & 5 \\
\hline sum & 11 & 14 & 14 & 9 & 9 & 21 & 19 & 12 & 15 & 14 & 13 & 14 & 6 \\
\hline$\%$ & $37 \%$ & $47 \%$ & $47 \%$ & $30 \%$ & $30 \%$ & $70 \%$ & $63 \%$ & $40 \%$ & $50 \%$ & $47 \%$ & $43 \%$ & $47 \%$ & \\
\hline
\end{tabular}

Table 1: Progress assessment of rhythm metrics for an individual participant for Phrases 1-4.

$$
\text { '+' - progress. '-' - no progress. }
$$

Overall, all the participants can be said to progress in at least one rhythm measure getting at least two pluses ( 3 speakers), which are assigned to VarcoC ( 3 pluses), \% V (2 pluses) and $\Delta \mathrm{C}$ (1 plus). None of the subjects has progressed in all the measures and for two tempos getting 12 pluses. The greatest progress has been accomplished in the performance of learners 21,22 and 29 who have been assigned 10 pluses each. The average number of pluses across subjects is 6. Interestingly, the tempo does not seem to be an influential factor in the achieved progress, as it can be observed that the higher 
number of pluses within each of the six measures is distributed equally for normal (3) and fast (3) tempo (\%V-F, $\Delta \mathrm{V}-\mathrm{N}, \Delta \mathrm{C}-\mathrm{F}, \mathrm{VarcoV}-\mathrm{N}, \mathrm{VarcoC}-\mathrm{N}, \mathrm{nPVI}-\mathrm{F})$. In other words, no pattern of improved scores for normal or fast tempo is to be found across all the measures. It must be remembered that Table1 presents averaged data for four phrases and there are considerable differences between phrases in the achieved progress. Table 2 shows the minimum and maximum number of pluses with the numbers of respective subjects for each of the four phrases and the measure which has been assigned the greatest number of pluses. What can be noticed here is the apparent inconsistency of speakers in their progress across measures. For instance, speaker 15 who in average data in Table 1 gets only 2 pluses for VarcoC and 1 plus for $\% \mathrm{~V}$ in Phrase 2, gets the highest number of 15 pluses in Phrase 4. Similarly, speaker 27 gets the minimum of 2 pluses in the averaged progress results and the maximum of 10 pluses in Phrase 3, Speaker 21 who scores 10 pluses in averaged results, gets 10 pluses in Phrase 2, which seems to be the only directly observed consistency across phrases.

\begin{tabular}{|l|l|l|l|}
\hline Phrase & Min. nr of + & Max. nr of + & Measure with the greatest nr of + \\
\hline $\mathbf{1}$ & $0($ speaker 25$)$ & $9($ speaker 10$)$ & $\Delta \mathrm{C}(\mathrm{N}-18, \mathrm{~F}-19)$ \\
\hline $\mathbf{2}$ & $1($ speaker 15, 19) & $10($ speaker18, 21) & nPVI (F-19) \\
\hline $\mathbf{3}$ & 3 (speaker 4, 9, 13) & $10($ speaker 26, 27) & $\Delta \mathrm{V}(\mathrm{N}-20) \quad$ VarcoC $(\mathrm{F}-20)$ \\
\hline $\mathbf{4}$ & $1($ speaker 3, 10) & $8($ speaker 15) & $\% \mathrm{~V}(\mathrm{~F}-17)$ \\
\hline
\end{tabular}

Table 2: Minimum and maximum numbers of pluses for each of the phrases and the measure with the greatest number of pluses in each of the phrases.

The inconsistencies are noticeable also with regard to the rhythm measures within which the greatest progress has been attained. Table 1 shows that the maximum of 21 subjects progressed in $\Delta \mathrm{C}$ scores (fast tempo) and 19 subjects in VarcoV (normal tempo), while the analysis of individual phrases reveals that the each measure undergoes some degree of change. In Phrasel the greatest number of speakers have improved in terms of $\Delta \mathrm{C}$ normal tempo (18), and fast tempo (19). In Phrase 2, it is nPVI (fast speech) with 19 speakers. In Phrase 3 , it is $\Delta \mathrm{V}$ (normal tempo) and VarcoC (fast tempo) with 20 speakers each. Finally, in Phrase4, \%V (fast tempo) with 17 speakers is the leading measure. Taking into consideration the progress of mean scores for all the phrases within individual measures according to the criteria formulated above and depicted in Table 3 , the improvement can be noticed for all the phrases, except for VarcoC (which surprisingly gets the maximum number of pluses in Phrase 3). Partial progress (only normal or fast tempo score has improved) can be observed in $\Delta \mathrm{C}$ and nPVI. The between-phrase differences may substantially contribute to the differences in the assessed progress between phrases. They included length differences, with Phrases 1 and 2 being longer ( 11 syllables each), and Phrases 3 and 4 being shorter ( 5 and 7 syllables), and consequently the differences in the numbers and durations of vocalic and consonantal intervals. Particular phrases may also contain various articulatory challenges with which different learners deal in different ways, and this in turn may affect the timing relations within phrases and consequently the rhythm measures scores. The $\% \mathrm{~V}$ scores do not improve, but they are in close proximity, not exceeding the native score for more than 1.0, and thus classified as progress. 


\begin{tabular}{|l|c|l|l|c|c|}
\hline \multirow{2}{*}{ Metric } & \multirow{2}{*}{ tempo } & Rec.1 & Rec.2 & Progress & Native \\
\cline { 2 - 6 } & & mean & mean & mean & mean \\
\hline \multirow{2}{*}{ V\% } & $\mathrm{N}$ & 39.8 & 40.2 & + & 39.6 \\
\cline { 2 - 6 } & $\mathrm{F}$ & 40.2 & 40.6 & + & 39.6 \\
\hline \multirow{2}{*}{$\Delta \mathbf{V}$} & $\mathrm{N}$ & 50.3 & 52.6 & + & 52.2 \\
\cline { 2 - 6 } & $\mathrm{F}$ & 46.6 & 46.8 & + & 46.8 \\
\hline \multirow{2}{*}{$\Delta \mathbf{C}$} & $\mathrm{N}$ & 89.3 & 86.0 & + & 87.2 \\
\cline { 2 - 6 } & $\mathrm{F}$ & 74.8 & 73.8 & - & 68.3 \\
\hline \multirow{2}{*}{ varcoV } & $\mathrm{N}$ & 47.5 & 50.9 & + & 54.9 \\
\cline { 2 - 6 } & $\mathrm{F}$ & 49.7 & 50.8 & + & 57.8 \\
\hline \multirow{2}{*}{ varcoC } & $\mathrm{N}$ & 57.1 & 57.4 & - & 60.2 \\
\cline { 2 - 6 } & $\mathrm{F}$ & 55.2 & 55.9 & - & 59.0 \\
\hline \multirow{2}{*}{ nPVI } & $\mathrm{N}$ & 51.1 & 53.4 & + & 58.8 \\
\cline { 2 - 6 } & $\mathrm{F}$ & 51.6 & 50.7 & - & 66.3 \\
\hline
\end{tabular}

Table 3: Assessing progress in the performance of rhythm measures between Recording 1 and Recording 2 for Phrases 1-4 with the scores of native speakers of English. '+' - progress. '-' - no progress.

The improvement scores presented in Tables 1-3 seem to be randomly distributed across phrases and speakers. In order to verify whether there are significant statistical differences between the rhythm metric scores obtained by the group of Polish learners of English between two recordings, a statistical analysis of repeated measures design has been employed and presented in Table 4.

\begin{tabular}{|c|c|c|c|c|c|c|c|c|c|c|c|c|}
\hline measure & \multicolumn{2}{|c|}{$\% \mathrm{~V}$} & \multicolumn{2}{|c|}{$\Delta \mathbf{V}$} & \multicolumn{2}{|c|}{$\Delta \mathrm{C}$} & \multicolumn{2}{|c|}{ VarcoV } & \multicolumn{2}{|c|}{ VarcoC } & \multicolumn{2}{|c|}{ nPVI } \\
\hline tempo & $\mathbf{N}$ & $\mathbf{F}$ & $\mathbf{N}$ & $\mathbf{F}$ & $\mathbf{N}$ & $\mathbf{F}$ & $\mathbf{N}$ & $\mathbf{F}$ & $\mathbf{N}$ & $\mathbf{F}$ & $\mathbf{N}$ & $\mathbf{F}$ \\
\hline$p$ & 0.12 & & .02 & 0.41 & & & 0.00 & 0.16 & & & 0.0 & 0.247 \\
\hline
\end{tabular}

Table 4: The results of one-tailed paired t test verifying significant differences in L2 English between two recordings, $\mathrm{N}=30$.

It shows that statistically significant differences have been achieved only in terms of $\Delta \mathrm{V}$ normal tempo $(p=0.0266)$ and VarcoV normal tempo $(p=0.0002) . \Delta \mathrm{C}$ in fast tempo and nPVI in normal tempo obtained scores close to significance level $(p=0.0709$ and $p=0.0608$ respectively).

\section{Discussion}

The general assumption of the experiment presented here is that with increased exposure to English and regular formal instruction concerning English pronunciation, L2 speech rhythm should improve and approximate native speech rhythm production. It has already been confirmed that general proficiency of non-native speakers of English is a key factor contributing to the successful production of rhythmic patterns in English (WaniekKlimczak 2009, Roach 2002). However, very few studies have provided evidence to rhythmic differences being connected with language learners' proficiency level. Dellwo 
et al. (2009) have not observed any significant changes in rhythmic scores for Spanish learners of English calculated twice after pre- and post-training recording sessions. Similarly, Gut (2012) has found no effect of either the training course in pronunciation or the stay abroad on rhythm measures in her comparison of the rhythm of language learners after a 6-month training and before and after a 9-month stay abroad in the target language country. One of the few studies that indicates the difference between learners at different competence levels is the one conducted by Stockmal et al. (2005). They found that the metrics able to show significant difference between beginners and more advanced learners of Latvian with L1 Russian are $\Delta \mathrm{C}$ and consonantal PVI. $\% \mathrm{~V}$ and nPVI have not been found to differentiate between the two groups of learners.

The results of the present study provide some weak support for Stockmal et al.'s findings in that the highest number of improved scores has been noted for $\Delta \mathrm{C}$ as well. The surprising and contradictory result is that this is true for the measure's fast speech version, while the normal speech $\Delta \mathrm{C}$, together with $\Delta \mathrm{V}$ for fast tempo, got the worst improvement scores. Statistical tests, however, have not verified the above results and revealed significant changes in the subjects' performance with respect to the vocalic measures $\Delta \mathrm{V}$ and VarcoV in normal tempo. The direction of change within the rhythm measures has been identified to lead towards the native English speakers' scores as depicted in Table 5 below.

\begin{tabular}{|l|c|c|c|}
\hline & Recording1 & Recording2 & Native English \\
\hline $\mathbf{\Delta V}$ & 50.3 & 52.6 & 52.2 \\
\hline VarcoV & 47.4 & 50.9 & 54.9 \\
\hline
\end{tabular}

Table 5: The mean results of $\Delta \mathrm{V}$ and VarcoV normal tempo obtained for Recording 1 and Recording 2, and compared to native English speakers' scores.

Although statistical differences have been identified for normal tempo, when analysed across all the measures, speech tempo does not appear to have a crucial impact on the learners' performance. In faster tempo L1 English can be expected to use more reduction, hence it becomes more difficult for its learners. Ideally, faster L2 English should be closer to normal tempo L1 English. However, no regularity of that kind is to be found within the data, as improved scores are similarly distributed for normal and fast tempo across the rhythm metrics.

Out of six measures, only two $(\Delta \mathrm{V}$ and $\mathrm{VarcoV})$ and only in normal tempo have revealed significant differences between scores. The fact that the progress was verified for two measures gives hope that, given some more time, the learners may manage to master their pronunciation to the degree that may be reflected by other rhythmic measures.

\section{Conclusion}

The analyses of rhythm metric scores for 30 subjects' pre- and post-training performance have revealed significant differences in terms of two vocalic measures $(\Delta \mathrm{V}$ and VarcoV). No substantial and consistent progress has been observed for the whole group 
and across all the measures. Although there are instances of observable improvement of scores in relation to native speakers' scores in the case of individual subjects and measures, one cannot speak of global progress and an essential change of participants' linguistic behaviour as:

- the average number of pluses indicating progress across all the measures for the group is 6 which covers only half of the 12 potential improvement points, suggesting that the progress is partial;

- different measure is 'the winner' in different phrases and the means for all phrases do not necessarily reflect reliably the tendencies observed in each individual phrase;

- the subject who is an outlier and performs progress in terms of the majority of measures according to one phrase scores much worse according to the remaining phrases.

The reasons why no clear and consistent change in all the rhythm measures is observed between the recordings are not obvious. The situation may result from the fact that rhythm metrics of the type discussed above do not constitute reliable indicators for changes in L2 proficiency, or that the differences in rhythmic proficiency of the learners between the two recordings are not large enough to be measurable with the metrics applied in this study. Perhaps, the type of training (mainly segment-based) contributes to the situation, as focusing on the qualities of individual sounds may disturb the acquisition and production of prosodically satisfactory utterances. As far as the exposure to English is concerned, it remains true that the majority of lecturers, including pronunciation teachers, are Polish, and their speech rhythm patterns may also diverge from the ones represented by native speakers of English.

Despite the prevailing conviction that teaching stress-timing of English is ineffective and should be omitted in favour of segment-based training (Jenkins 2000), the fact that English as performed by Polish learners reveals changes in the rhythm measure scores suggests that speech rhythm is teachable and should constitute an important element of formal instruction in the pronunciation teaching syllabuses.

\section{References}

Abercrombie, D. 1967. Elements of general phonetics. Edinburgh: Edinburgh University Press.

Adams, C. 1979. English Speech Rhythm and the Foreign Learner. The Hague: Mouton.

Asu, E.L., Nolan, F. 2005. Estonian rhythm and the Pairwise Variability Index. In: Proceedings, FONETIK 2005, Department of Linguistics, Göteborg University.

Avery, P. and Ehrlich, S. 1992. Teaching American English Pronunciation. Oxford: Oxford University Press.

Barry, W.J., Andreeva, B, Russo, M., Dimitrova, S. and Kostadinova, T. 2003. Do Rhythm Measures Tell us Anything about Language Type? In: D. Recasens, M.J.Solé and J. Romero, editors, Proceedings of the 15th International Congress of Phonetic Sciences (ICPhS 2003), Barcelona: 2693-2696.

Boersma, P. And Weenink, D. 2008. Praat:Doing phonetics by computer (verion5.0.29). Retrieved $14^{\text {th }}$ July 2008 , from <http://www.praat.org/>. 
Dauer, R. 1987. Phonetic and phonological components of language rhythm. Proceedings of the 11th International Congress of Phonetic Sciences, Tallin, Vol.5: 447-450.

Dauer, R. M. 1983. Stress-timing and syllable-timing reanalysed. Journal of Phonetics 11: 51-69.

Dellwo, V., F. Gutierrez Diez, and N. Gavalda. 2009. The development of measurable speech rhythm in. Spanish speakers of English In Actas de XI Simposio Internacional de Comunicacion Social, Santiago de Cuba: 594-597.

Dellwo, V. 2010. Influences of speech rate on the acoustic correlates of speech rhythm: An experimental phonetic study based on acoustic and perceptual evidence. PhDDissertation, Universität Bonn (electronic publication: http://hss.ulb.uni-bonn.de:90 /2010/2003/2003.htm).

Dellwo, V., Wagner, P. 2000. Relations between language rhythm and speech rate. Proceedings of the International Congress of Phonetic Science. Barcelona: 471-474.

Ferragne, E. and Pellegrino, F. 2008. Le rythme dans les dialectes de l'anglais: une affaire d'intensité ? Actes de Journées d'Etude de la Parole, Avignon, 9-13 juin 2008.

Grabe, E. and Low, E.L. 2002. Durational variability in speech and the rhythm class hypothesis. In: C. Gussenhoven and N. Warner (eds) Papers in Laboratory Phonology 7. Cambridge: CUP.

Gut, U. 2012. Rhythm in L2 Speech. In Gibbon, Dafydd (ed.), Speech and Language Technology. Poznań: 83-94.

Hayes, B. and S. Puppel. 1985. On the rhythm rule in Polish. In: van der Hulst, H. and N. Smith. (eds) Advances in non-linear phonology. Dordrecht: Foris Publications: 59-81.

Jenkins, J. 2000. The Phonology of English as an International Language. Oxford: Oxford University Press.

Jian, Hua-Li. 2004. On the syllable timing in Taiwan English, In B. Bel /. I. Marlien (eds) Proceedings of Speech Prosody 2004, Nara (Japan) 23-26 March 2004, ISCA Special Interest Group on Speech Prosody (SproSIG), 247-250.

Laver, J. 1994. Principles of phonetics. Cambridge: Cambridge University Press.

Low, E. L., Grabe E. and Nolan F. 2000. Quantitative characterization of speech rhythm: Syllable-timing in Singapore English. Language and Speech 43: 377-401.

Mok, P., Dellwo, V. 2008. Comparing native and non-native speech rhythm using acoustic rhythmic measures: Cantonese, Beijing Mandarin and English. Speech Prosody 2008, Campinas, 423-426.

Nespor, M. 1990. On the rhythm parameter in phonology, Roca Iggy M., (ed.), Logical Issues in Language Acquisition, Dordrecht: Foris: 157-175.

Ordin, M., Polyanskaya, L., Ulbrich, Ch. 2011. Acquisition of Timing Patterns in Second Language. INTERSPEECH 2011, 12th Annual Conference of the International Speech Communication Association, Florence, Italy, August 27-31, 2011, Florence, Italy; 08/2011.

Pike, K.L. 1945. The intonation of American English. Ann Arbor: University of Michigan Press.

Ramus, F., Nespor, M., and Mehler, J. 1999. Correlates of linguistic rhythm in the speech signal. Cognition, 72, 1-28. 
Roach, P. 2002. Studying rhythm and timing in English speech: Scientific curiosity, or a classroom necessity? In: E. Waniek-Klimczak and P. J. Melia (eds) Accents and Speech in Teaching English Phonetics and Phonology. Łódź Studies in Language Vol.5. Frankfurt am Main: Peter Lang: 199-206.

Rubach, J. and Booij, G.E. 1985. A grid theory of stress in Polish. Lingua 66, North Holland: 281-319.

Shport, I. 2009. The effect of oral proficiency on production of rhythm in spontaneous second language (L2) Japanese speech. The Journal of the Acoustical Society of America vol. 125: 2728-2728.

Stockmal, V., D. Marcus, and D. Bond. 2005. Measures of Native and Non-Native Rhythm in a Quantity Language. Language and Speech 48: 55-63.

Wagner, P.S. 2012. Speech rhythm in native and non-native Polish. Proceedings of the International Conference of Experimental Linguistics ExLing 2012: 27-29 August 2012, Athens, Greece.

Wagner, P.S., Dellwo, V. 2004. Introducing YARD (Yet Another Rhythm Determination) And Re-Introducing Isochrony to Rhythm Research. Speech Prosody 2004, Nara, Japan.

Waniek-Klimczak, E. 2009. Sources of difficulty in the acquisition of English rhythm by Polish learners: A developmental perspective. In M. Wysocka (ed.) On Language Structure, Acquisition and Teaching: 359-169. Katowice: Wydawnictwo Uniwersytetu Śląskiego.

Waniek-Klimczak, E. 2005. Temporal Parameters in Second Language Speech: An Applied Linguistic Phonetics Approach, Łódź: Wydawnictwo Uniwersytetu Łódzkiego.

White, L. and Mattys, S. 2007. Rhythmic typology and variation in first and second languages. In P. Prietro, J. Mascaró, and M. J. Solé (eds) Segmental and prosodic issues in romance phonology (Current issues in linguistic theory series). Amsterdam, Philadelphia: John Benjamins. 


\section{Appendix 1}

Phrase1: should be considered stronger than the other

\begin{tabular}{|c|c|c|c|c|c|c|c|c|c|c|c|c|c|c|c|c|c|c|c|}
\hline $\int$ & $\partial$ & $\mathrm{d}$ & $\mathrm{b}$ & i: & $\mathrm{k}$ & $\partial$ & $\mathrm{n}$ & $\mathrm{s}$ & I & $\mathrm{d}$ & $\partial$ & $\mathrm{d}$ & $\mathrm{s}$ & $\mathrm{t}$ & $\mathrm{r}$ & $\mathrm{p}$ & $y$ & $\mathrm{~g}$ & $\partial$ \\
\hline C & $V$ & $C$ & $C$ & V & C & $V$ & C & C & V & C & V & C & $C$ & C & C & V & $C$ & $C$ & $V$ \\
\hline б & $\partial$ & $\mathrm{n}$ & б & $\mathrm{i}$ & $\Lambda$ & д & $\partial$ & & & & & & & & & & & & \\
\hline$C$ & $\mathrm{~V}$ & $C$ & $C$ & $\mathrm{~V}$ & $\mathrm{~V}$ & $C$ & $\mathrm{~V}$ & & & & & & & & & & & & \\
\hline
\end{tabular}

Phrase2: and at last the North Wind gave up the attempt

\begin{tabular}{|c|c|c|c|c|c|c|c|c|c|c|c|c|c|c|c|c|c|c|c|c|}
\hline$\partial$ & $\mathrm{n}$ & $\mathrm{d}$ & $\partial$ & $\mathrm{t}$ & 1 & $\mathrm{at}$ & $\mathrm{S}$ & $\mathrm{t}$ & б & $\partial$ & $\mathrm{n}$ & $x_{x}$ & $\theta$ & $\mathrm{W}$ & I & $\mathrm{n}$ & $\mathrm{d}$ & $\mathrm{g}$ & eI & $\mathrm{V}$ \\
\hline V & C & $C$ & V & C & C & V & C & C & C & V & C & V & C & C & V & C & $C$ & $C$ & V & C \\
\hline$\Lambda$ & $\mathrm{p}$ & ठ & $\mathrm{i}$ & $\partial$ & $\mathrm{t}$ & $\mathrm{e}$ & $\mathrm{m}$ & $\mathrm{p}$ & $\mathrm{t}$ & & & & & & & & & & & \\
\hline V & C & $C$ & V & V & C & V & C & C & C & & & & & & & & & & & \\
\hline
\end{tabular}

Phrase3: wrapped in a warm cloak

\begin{tabular}{|l|l|l|l|l|l|l|l|l|l|l|l|l|l|}
\hline $\mathrm{r}$ & $\mathfrak{x}$ & $\mathrm{p}$ & $\mathrm{t}$ & $\mathrm{I}$ & $\mathrm{n}$ & ə & $\mathrm{W}$ & ○: & $\mathrm{m}$ & $\mathrm{k}$ & $\mathrm{l}$ & əU & $\mathrm{k}$ \\
\hline $\mathrm{C}$ & $\mathrm{V}$ & $\mathrm{C}$ & $\mathrm{C}$ & $\mathrm{V}$ & $\mathrm{C}$ & $\mathrm{V}$ & $\mathrm{C}$ & $\mathrm{V}$ & $\mathrm{C}$ & $\mathrm{C}$ & $\mathrm{C}$ & $\mathrm{V}$ & $\mathrm{C}$ \\
\hline
\end{tabular}

Phrase4: then the Sun shone out warmly

\begin{tabular}{|l|l|l|l|l|l|l|l|l|l|l|l|l|l|l|l|l|l|}
\hline ठ & $\mathrm{e}$ & $\mathrm{n}$ & $\mathrm{d}$ & $\mathrm{\partial}$ & $\mathrm{S}$ & $\mathrm{\Lambda}$ & $\mathrm{n}$ & $\mathrm{J}$ & $\mathrm{D}$ & $\mathrm{n}$ & $\mathrm{a} U$ & $\mathrm{t}$ & $\mathrm{w}$ & $\mathrm{O}$ & $\mathrm{m}$ & $\mathrm{l}$ & $\mathrm{i}$ \\
\hline $\mathrm{C}$ & $\mathrm{V}$ & $\mathrm{C}$ & $\mathrm{C}$ & $\mathrm{V}$ & $\mathrm{C}$ & $\mathrm{V}$ & $\mathrm{C}$ & $\mathrm{C}$ & $\mathrm{V}$ & $\mathrm{C}$ & $\mathrm{V}$ & $\mathrm{C}$ & $\mathrm{C}$ & $\mathrm{V}$ & $\mathrm{C}$ & $\mathrm{C}$ & $\mathrm{V}$ \\
\hline
\end{tabular}

